\title{
Nursing undergraduates' perception of preparedness using patient electronic medical records in clinical practice
}

\author{
AUTHORS \\ LYNDALL MOLLART PhD, RN, RM ${ }^{1}$ \\ RACHEL NEWELL RN RM ${ }^{1}$ \\ DANIELLE NOBLE RN ${ }^{1}$ \\ SARA K GEALE PhD RN ${ }^{1}$
}

CAROL NORTON RN RM ${ }^{1}$

ANTHONY P O'BRIEN PhD RN ${ }^{1}$
1 School of Nursing and Midwifery, University of Newcastle, Callaghan, New South Wales, Australia

\section{CORRESPONDING AUTHOR}

LYNDALL MOLLART School of Nursing and Midwifery, University of Newcastle, University Drive, Callaghan NSW 2308, Australia. Phone: +61 24985 4481. Email: Lyndall.mollart@newcastle.edu.au ORCiD: 0000-0002-8390-0658

\section{ABSTRACT}

Objective: To investigate third-year undergraduate nursing students' perceptions and views on being prepared for using patient electronic medical records (EMR) in clinical placement after using only paper-based documentation during their education program; and their opinion on the introduction of EMR in the university simulated learning environments to be work ready.

Background: Contemporaneous clinical practice in many countries now requires nurses to competently use patient EMR including electronic observation and medication charts. However, Australia has been slow in introducing this learning into undergraduate nursing programs. For this reason, there is a knowledge gap examining nursing students' viewpoints on learning EMR in their undergraduate program in preparation for the clinical environment and future registered nurses in Australia.

Methods: All third-year students enrolled in the undergraduate nursing program at one regional metropolitan university in New South Wales (including three campuses) were invited to complete an electronic questionnaire. This survey included questions on the students' perceptions on their confidence and preparedness using EMR in clinical practice based on their current paper-based learning in the university simulation laboratories; and their opinions on the benefits of integrating EMR learning into the undergraduate nursing curriculum.

Results: Seventy third-year nursing students completed the questionnaire, a response rate of $13.2 \%$. Most respondents $(71.1 \%)$ did not feel prepared to use EMR in the clinical setting after only learning paper-based documentation and $81.7 \%$ did not feel confident accessing patients EMR the first time. Nearly all students (98.5\%) believed they would be more confident using EMR initially in their clinical placements if there had been opportunity to practice using EMR in the university simulation laboratories. There was a significant difference with female participants perceived improved confidence accessing patients EMR, if EMR was integrated into the university simulated laboratories compared to the male participants $(p=0.007)$.

Conclusion: In this study, third year nursing students believed that learning to use an EMR program in the university simulated environment will increase 
their confidence and preparedness when on clinical placement and be work ready as registered nurses.

Implications for research, policy and practice: This study showcases the importance of preparing nursing students for entering the workforce as confident and competent new graduate registered nurses and integrating health informatics and digital health technologies universities in undergraduate nursing programs in Australia. Future studies on Australian student's experience with the introduction of an academic EMR program is recommended.

What is already known about the topic?

- Using patient electronic medical records (EMR) is included in the nurse's scope of practice in healthcare services worldwide.
- This scope of practice requires that nursing students learn the skills to use EMR in a safe environment.

What this paper adds:

- Third year nursing students are not being prepared to use EMR in the clinical setting based on paperbased learning

- Majority of students identified the need to learn to use EMR in university simulation labs prior to clinical placement

- Effective integration of EMR into nursing undergraduate curriculum in Australia is essential

Keywords: Nursing education, electronic health records, student nurses, clinical skills/competency.

\section{OBJECTIVE}

This study investigated third year undergraduate nursing students' perceptions and views on being prepared for using patient EMR in clinical placement after using only paperbased documentation during their education program; and their opinion on the introduction of EMR in the university simulated learning environments (SLEs) and being work ready.

\section{BACKGROUND}

Contemporaneous clinical practice in many countries now requires registered nurses to competently use patient electronic medical records (EMR) including observation/ vital signs and medication charts. ${ }^{1-4}$ In those countries that have introduced EMR, it has been demonstrated to reduce adverse events due to miscommunication, or incomplete information and to provide guidance for data, clinical assessments and best practice decision-making. 5 With the improvement in patient safety, and better patient outcomes, EMR has now be introduced into most Australian public hospitals with a reported $48 \%$ of integrated EMR systems rolled out across the public healthcare sector in $2017 .^{6}$

Research, in the USA, Canada, Singapore, South Korea and UK where EMR has been implemented into the undergraduate nursing program, has shown that nursing students are better prepared for clinical placement with skill mastery in accessing patient electronic data and documentation after using e-documentation programs in an academic learning environment..$^{7-12}$ However, digital health technology using EMR and electronic patient observation charts have yet to be fully integrated into the teaching of clinical skills and simulation labs in undergraduate nursing university curricula in many countries including Australia. ${ }^{13,14} \mathrm{~A}$ recent scoping review found only two Australian studies published on education and training on EMRs for healthcare professionals and students in the 19 year period, however both studies focused on medical students (January 2000-October 2019). ${ }^{4}$ This apparent lack of curricula integration of digital health technology in Australian nursing programs has the potential to leave nursing students underprepared for their clinical experience in both public and private healthcare facilities. ${ }^{14,15}$ In Australia, the Australian Nursing and Midwifery Accreditation Council (ANMAC) has identified that "it is essential that the management of information and use of digital technology should be a priority in entry-to-practice higher education nursing programs" (p.19) ${ }^{16}$.

An integrated review by Mollart et al. recommended that the implementation of an EMR program in an academic setting has the potential to increase the nursing student's capacity for graduate employment, with the opportunity to build on professional attributes and develop transferable skills that are common to a range of nursing roles in health services. ${ }^{15}$, ${ }^{17}$ Research studies have reported that electronic medical records provide the student nurse with detailed digital access to the patient history and health condition and encourage the use of critical thinking and clinical decision making. ${ }^{8,18 \text {, }}$ ${ }^{19}$ Simulation conducted in university clinical laboratories provides the ideal place for nursing students to familiarise and explore electronic EMR information system whilst in a safe and supported environment. ${ }^{2,8-10,18-23}$ Currently, there is no research exploring Australian nursing students' viewpoints on the challenges using EMR in the clinical setting with paper-based learning, and their opinions on the integration of EMR into the undergraduate curriculum that might better prepare them for clinical practice. The aim of this study was to explore third year undergraduate nursing students' personal perception of their preparedness 
to use patient medical records and charts based on their educational curriculum.

\section{METHOD}

\section{DESIGN AND SAMPLE}

A cross-sectional descriptive study design with a selfadministered questionnaire was used for this study. A convenience sample of all third-year nursing students $(n=530)$ enrolled in the undergraduate nursing program at a regional metropolitan university in NSW, Australia (which included three campuses) were invited to participate. The inclusion criteria were undergraduate nursing students enrolled in year three, thus the only exclusion criteria were students not enrolled in third year of the undergraduate nursing program.

\section{DATA COLLECTION}

After receiving university ethics approval (UON HREC 2018-0488), an invitation email was sent to all third-year nursing students. The email outlined the study and asked for voluntarily participation by students completing a short 10-minute electronic anonymous questionnaire (via SurveyMonkey) between 1 March to 31 May 2019. In addition to the email, the study invite was posted on the electronic Blackboard $(\mathrm{Bb}) 3^{\text {rd }}$ year course site and posters were displayed at the three campuses. Reminder emails and Bb announcement occurred two weeks after original invitation to encourage participation. The study invitation included the study information sheet which outlined that students had the right to withdraw from the study without explanation, however depending on the stage of the study, withdrawal of provided data would not be possible due to de-identified questionnaire results being aggregated and anonymised. Informed consent was implied when the student completed the online questionnaire.

\section{SURVEY TOOL}

The survey tool was developed based on the integrated review by the authors as there is no validated tool currently. ${ }^{15}$ The questions attempted to gather the third year undergraduate nursing students' personal perceptions on their preparedness for using EMR in clinical practice modelled on the current paper based learning delivered in SLEs; and the possible impact of integrating EMR learning in university SLEs on their confidence and preparedness for hospital clinical placements. The questionnaire had three sections: 1) demographic details and training during clinical placement using EMR; 2) Likert style questions and open ended questions on: student's perception of confidence and preparedness when starting clinical placement using EMR and electronic Standard Adult General Observation [eSAGO] chart after learning to use paper-based patient records, observation charts and the medication information booklet
(MIMS); and 3) Likert and open-ended question asking for their personal view on usefulness of learning EMR, eSAGO chart, and electronic medicines information in the university SLEs, in preparation for hospital clinical experience.

To ensure that the student participants' responses were anonymous, the option to collect computer IP addresses was switched to 'No' and confidentiality was maintained by not using a shared account. The study information on the first 'page' of the participant information sheet included researcher contact details, reasons for the research and the individual participant's right to withdraw at any point by exiting the questionnaire. The chief investigator (LM) was not involved in teaching third year nursing students or involved in SLEs or clinical placement (minimising bias).

\section{DATA ANALYSIS}

The student questionnaire scores were collated and analysed using descriptive and inferential comparative analysis. Quantitative data was analysed using the Statistical Package for Social Science V24.o (SPSS). Non-parametric MannWhitney U test was used to test for mean ranking differences for dependent variables (age group, gender and campus site). Age and gender were chosen as dependent variables based on previous research., 24, 25 Levels of significance are reported at $\mathrm{p}<0.05$. Age groups was further categorised into two groups i.e. 37 years and under and over 37 to have sufficient numbers to allow further analysis with non-parametric Mann-Whitney U test.

The open-ended question was analysed using a qualitative thematic approach. Content analysis of the comments was undertaken using the method described as fundamental or generic qualitative description, which aims to discover and understand a phenomenon, or the perspectives of people, with themes generated from cumulative counts of like comments. ${ }^{26,27}$ Following the general principles of qualitative data analysis and to establish reliability, two of the authors (LM, RN) first familiarised themselves with the data by reading through students' comments and reflecting on them using margin notes, highlighting keywords and then counting the number of key findings to generate initial themes to compare so that the analysis was reflexive and interactive. ${ }^{26}$ Open discussions were held with all authors to refine and re-conceptualise themes until reaching consensus.

\section{RESULTS}

\section{DEMOGRAPHICS}

From a possible 530 students, 70 students completed the survey, a response rate of $13.2 \%$ which is reflective of other studies response rates surveying students with online questionnaires. ${ }^{28,29}$ As shown in Table 1 , participant ages ranged from 20-55 years of age (Median 23 years, SD:10) and over half of participants (56.5\%) had previously received 
training as Assistants in Nursing (AIN), and four (5.8\%) as Enrolled Nurses (ENs). Most respondents were female (87.14\%) which is consistent with the nursing student population and spanned across the three university campuses.

\section{TABLE 1: RESPONDENTS DEMOGRAPHICS ( $\mathrm{N}=70)$}

\begin{tabular}{|c|c|c|}
\hline \multicolumn{2}{|l|}{ Characteristics } & \multirow{2}{*}{$\begin{array}{r}\text { Frequencies } \mathrm{n}(\%) \\
20(28.6)\end{array}$} \\
\hline Age (years) & $20-24$ & \\
\hline & $25-29$ & $11(15.7)$ \\
\hline & $30-34$ & $15(21.4)$ \\
\hline & $35-39$ & $8(11.4)$ \\
\hline & $40-44$ & $4(5.7)$ \\
\hline & $45-49$ & $6(8.6)$ \\
\hline & $50-55$ & $6(8.6)$ \\
\hline & Total & $70(100)$ \\
\hline \multirow[t]{2}{*}{ Gender } & Female & $61(87.15)$ \\
\hline & Male & $9(12.9)$ \\
\hline \multirow[t]{2}{*}{ Enrolment status } & Domestic student & $68(97.1)$ \\
\hline & International student & $2(2.9)$ \\
\hline \multirow[t]{2}{*}{ Other qualifications } & Assistant in Nursing & $39(56.5)$ \\
\hline & Enrolled nurse & $4(5.6)$ \\
\hline
\end{tabular}

Just over half of student participants $(55.7 \%, \mathrm{n}=39)$ had received preliminary training in using the EMR and SAGO chart $(51.4 \%, n=36)$ during their clinical placement at a public hospital at some point in the previous three years. There were no statistically significant differences found between receiving preliminary hospital training in EMR and confidence accessing EMR ( $p=0.891)$ and documenting in $\operatorname{EMR}(\mathrm{p}=0.754)$ in the clinical setting.

Reflecting upon their level of confidence in accessing and documenting using electronic files, most respondents (81.7\%) did not feel confident accessing patient EMR the first time in clinical placement, and documenting (65.2\%) in patient EMR (Table 2). There were no statistically significant differences with participants EMR confidence levels and gender, however respondents aged 20 to 37 years were more confident accessing EMR the first time, than participants over 37 years of age $(\mathrm{p}=0.047)$. Reflecting on their confidence using eSAGO charts, $60 \%$ students did not feel confident $(29 \%$ not at all confident, 31.9\% not so confident) and 59.4\% didn't feel confident documenting observations in eSAGO charts (Table 2). No statistically significant differences were found with confidence using eSAGO charts and variables of age and gender.

Nearly three quarters (71.1\%) of participants did not feel prepared to use EMR in the clinical setting based on learning paper-based documents at the university SLE (Table 2). Additionally, student participants were asked for their opinion on how useful it would be to familiarise themselves with using EMR in the university SLEs in preparation for their clinical placement experience. In response to this question 98.5\% of respondents believed that learning EMR in the simulation environment would be extremely (76.1\%), or very useful (22.4\%). Most participants (83.6\%) believed learning e-observations charts would be extremely useful (59.7\%) or very useful (23.9\%).

Participants were asked to reflect on their education program, and nearly all thought they would have been more confident accessing a patient's EMR for the first time on clinical placement, if they had learnt EMR (98.5\%) or eSAGO charts (95.5\%) in SLEs as preparation for practice. There was a significant difference with female participants perceived, improved, confidence accessing patients EMR, if EMR was integrated into the university SLEs, compared to the male participants $(\mathrm{p}=0.007)$. There was no significant difference with age $(p=0.49)$.

\section{THEMES}

Most participants (82.8\%) provided their opinion in the openended question on what they perceived was the impact of only learning to use paper-based documentation in university SLEs for student preparedness to use EMR in their first clinical placement. Four main themes emerged from the qualitative open-ended data: 1) paper-based learning provides a foundation for using EMR in clinical practice; 2 ) feeling unprepared for using EMR; 3) need to learn both paper-based and EMR; and, 4) paperbased system is outdated.

The first theme paper-based learning gave me a foundation for using EMR in clinical practice was identified with 13 respondent comments. Student respondents viewed paper based learning as providing a basic understanding of recording information and learning experience in preparation for clinical placement, with one student commenting "I think

\section{TABLE 2: CONFIDENCE AT FIRST CLINICAL PLACEMENT USING ELECTRONIC DOCUMENTATION}

\begin{tabular}{|c|c|c|c|c|c|}
\hline Confidence & $\begin{array}{r}\text { Not at all } \\
\text { confident } \\
\mathbf{N}(\%)\end{array}$ & $\begin{array}{r}\text { Not so } \\
\text { confident } \\
\mathrm{N}(\%)\end{array}$ & $\begin{array}{r}\text { Somewhat } \\
\text { confident } \\
N(\%)\end{array}$ & $\begin{array}{r}\text { Very } \\
\text { confident } \\
\mathrm{N}(\%)\end{array}$ & $\begin{array}{r}\text { Extremely } \\
\text { confident } \\
\mathbf{N}(\%)\end{array}$ \\
\hline Accesiing patient EMR & $22(31.9)$ & $33(47.8)$ & $8(11.6)$ & $5(7.3)$ & $1(1.5)$ \\
\hline Documenting in patient EMR & $16(23.2)$ & $29(42)$ & $19(27.5)$ & $4(5.8)$ & $1(1.5)$ \\
\hline Using e-SAGO chart & $20(29)$ & $22(31.9)$ & $21(30.4)$ & $4(5.8)$ & $2(2.9)$ \\
\hline Documenting observations in e-SAGO chart & $15(21.7)$ & $26(37.7)$ & $24(34.8)$ & $1(1.5)$ & $3(4.4)$ \\
\hline
\end{tabular}


learning paper-based documentation provided some prerequisite foundation for understanding how to use e-documentation because the categories and titles are (mostly) similar [to EMR]" (S35) and another student "Paper documentation may be useful in first year to get a grounding as it has all instructions on them-will also help when placed at a hospital that is still paper based"( 338$)$.

The second theme feeling unprepared for EMR was reflected by 25 students' comments. The participating students used words to describe their feelings such as "inadequate", "nervous and unsure" when attending clinical placement where EMR was the norm. Comments included:

"I was not prepared, I felt out of my depth. It was like I had spent a solid amount of time learning something that would not be applied" (S46).

"I was not really prepared using the EMR as I was not trained to use it in SLE. Felt a bit lost and lack confidence" $\left(\mathrm{S}_{53}\right)$.

"I actually feel like a fish out of water in labs and on the ward because I'm not prepared for using the medchart (eSAGO)" (S45).

The third theme Need to learn both paper and electronic was identified by 12 student respondents with comments such as "As some charts are still on paper in the NSW health facilities, it has been useful to use paper charts in SLE's" (S70) and "Paper based training is still worthwhile as the principles remain the same, however, it would be worthwhile having training in university using EMR".(S69)

The fourth and final theme paper-based learning is outdated was expressed by five student comments. Students believed that learning paper-based documentation was not providing them with contemporary relevant clinical skills to make them work ready, with comments such as:

"Paper-based documentation is becoming more irrelevant to clinical application as most hospitals are moving to EMR... Now, when graduating nurses begin practicing, they will already be behind having not used EMR.” (S23),

"Using paper-based documentation in SLE is pointless because no hospitals are using paper any more, everywhere has EMR. First time going on placement you have no idea how to use it because you get taught on paper and it's not relevant to the clinical setting"(S17)

"We need to practice exactly what we will do in a job, practicing void practices is a waste of great learning time/experience" (S15).

\section{DISCUSSION}

Research studies have investigated nursing student's attitudes in the use of information technology in clinical practice as opposed to the university setting ${ }^{30-32}$. However, this study is the first to explore nursing student's confidence and skill using patient EMR documents prior to the introduction of EMR into their undergraduate curriculum, and their perception on the usefulness and preparedness of integrating EMR into undergraduate simulation learning. Although a low response rate, the sample completing the survey was representative of gender and years of age distribution based on other studies conducted with third year students in Australia. ${ }^{33,34}$

Both public and private healthcare facilities are introducing EMR in the clinical setting and it is recognised that student nurses need to be able to access and use the EMR programs and become knowledgeable and skilled in the use of electronic healthcare systems. 35 While education providers currently teach clinical paper-based documentation as a mandatory requirement of safe effective clinical care, many countries are still not teaching undergraduate nursing students how to use EMR in readiness for clinical practice. ${ }^{4,13,14}$

According to Nursing Informatics Australia and Health Informatics Society of Australia (NIA \& HISA), education of undergraduate nurses in readiness to enter the workforce must include theoretical and practical tutoring on digital information and practical application in the healthcare setting. ${ }^{6}$ Our study reported that $44 \%$ of third year students had received some basic EMR training from the hospitals and only $29 \%$ felt "somewhat" or "very prepared" to use EMR for the first time in the clinical setting. This finding is similar to a study conducted with 215 UK first to third year nursing and midwifery students who had completed at least one clinical placement. ${ }^{37}$ Baillie et al. found 60\% had not received any training from the hospitals and only $16 \%$ of students felt prepared to use EMR. ${ }^{37}$ The responsibility for preparation of student nurses to meet future health, aged care and disability needs of the community should be a shared responsibility across the tertiary education system and the healthcare sector in conjunction with professional bodies..$^{6}$

Our study findings identified that many student participants felt underprepared in accessing and using EMR based on their paper-based university learning (71.1\%) which potentially could have a negative impact on their ability to provide person-centred care and respond appropriately to patient condition deterioration, or improvement. $3^{8}$ Previous research has recommended that having EMR education in undergraduate programs improves the student's ability to detect critical cues and apply critical thinking. ${ }^{8,19}$ As healthcare organisations use a variety of EMR informatic programs, it is recommended that universities use a fit-forpurpose academic EMR program so the skills students gain can be applied to any EMR program in the clinical setting, and meaningful 'real-life' scenarios can be scaffolded in the three year program. $5,15,23$

The qualitative findings of our study identified themes on the lack of preparedness for clinical placement, which are similar to Bailie et al. study with focus group sessions. ${ }^{37}$ 
In their focus groups, student participants believed it was beneficial to learn to use EMR in the undergraduate education program, as some students would complete their pre-registration program with no practice of EMR and then be ill-prepared as a newly qualified nurse. ${ }^{37}$ It is concerning that third-year students in this study did not feel confident or prepared, in using or documenting using the hospital electronic documentation system due to the lack of prerequisite education in their undergraduate curricula. Also, of concern is that these students will be registered nurses within the next eight months and be required to practice safely, effectively and collaboratively, as per the Nursing and Midwifery Board of Australia (NMBA) Code of Conduct for Nurses. ${ }^{39}$ If third year student nurses are not work ready in the use of EMR then they may be unable to respond appropriately in a safe and effective manner as outlined by the recently released NMBA Decision-making framework for nursing and midwifery. ${ }^{40}$

Over half of the students (55.7\%) had received some basic training in EMR at a hospital and yet they did not feel confident accessing or documenting patient's EMR. The reasons and barriers cited by students include lack of access to EMR on the wards; and, mentors and supervising nurses have difficulty finding time to teach students to use EMR in busy wards. ${ }^{21,37}$ Whereas nearly all respondents (98.7\%) believed that learning to use EMR should be integrated into the university simulation laboratory sessions. The integration of EMR into the curriculum, both theory and simulation learning, would better prepare them for the real world of clinical practice. EMR systems and educational programs have been successfully integrated into undergraduate nursing curriculum in other countries such as USA, ${ }^{19,21,41}$ Canada, ${ }^{10}$ South Korea, ${ }^{7,18}$ and Singapore, ${ }^{24}$ however it is unclear why there has been a delayed interval in Australian universities. The Australian Nursing and Midwifery Accreditation Council (ANMAC) accreditation standards makes specific mention of prioritising the development and application of knowledge and skills in health informatics and health technology in the undergraduate nursing program content. ${ }^{16}$

Healthcare organisations are wanting nurses to be skilled in the use of the technology and information management relating to patient care. ${ }^{18}$ However, it is recognised that using EMR systems can be time consuming tasks for new nurses as they assimilate into the healthcare system. ${ }^{11}$ To successfully implement a specific academic EMR program, it is recommended that integration is done in five stages: planning, product demonstration, faculty development and training, curriculum threading and implementation and evaluation. ${ }^{42}$ Our study findings demonstrated that students recommended EMR learning should commence in the first year of the program, this in turn would help the student to learn in a supportive scaffolded educational environment, rather than on clinical placement when nursing staff have limited time to provide teaching and students feel they are a burden. Other studies have also recommended that EMR is introduced to the first-year students, and then scaffolded learning to occur over the course of the three-year degree. ${ }^{9,} 43$ This could be achieved by introducing increasing complexity and real-life scenarios with additional electronic forms from first year through to the end of the undergraduate program., 10

\section{LIMITATIONS}

The third-year students were asked to reflect upon their first-year clinical placement using EMR to complete some sections of the survey, and recall bias may have influenced their answers and possible selection bias (those who responded and those who did not). Many students of the third-year cohort did not opt into the study despite receiving personal emails, posters displayed on campus and posting on the course announcement Blackboard page. Other studies have also shown low response rates when asking students to respond to online surveys. ${ }^{28,29}$ This study's findings are tentative and can't be generalised to the whole population of nursing students due to low response rate and using an opinion-based questionnaire compiled from the extant literature. However, the combined data provides an illustration of the importance of providing EMR education and supplement with paper-based documentation.

\section{CONCLUSION AND IMPLICATIONS FOR RESEARCH, POLICY AND PRACTICE}

As nursing clinical practice shifts from paper-based patient record documentation to electronic record-keeping worldwide, there is an imperative need to include EMR in Australian nursing undergraduate education. Students are understandably anxious when they attend their first and arguably other clinical experiences, as the experience is time-limited. One could suggest that their anxiety about not knowing how to use EMR, is also a reflection on their overall anxiety about preparedness for clinical practice generally and this possibly warrants further research. The majority of third year students in this study found the integration of EMR into educational instruction in the first year of study and, if scaffolded, would build on their confidence and preparedness for clinical practice. In the context of this study the qualitative comments provide a strong justification for further developing the simulation environment curricula activities to include EMR in all case based and practice scenarios, as it is now considered the norm in clinical practice.

Conflict of Interest Statement: No conflict of interest identified by any authors: in employment, consultancies, stock ownership, honoraria, paid expert testimony, patent applications/registrations, and grants or funding.

There was no funding received for the work reported in the paper, or for the writing of the manuscript. 


\section{REFERENCES}

1. Nickitas DM, Nokes KM, Caroselli C, Mahon PY, Colucci DE, Lester RD. Increasing nursing student communication skills through electronic health record system documentation. Comput Inform Nurs. 2010; 28(1): 7-11.

2. Bowling AM. Incorporating electronic documentation into beginning nursing courses facilitates safe nursing practice. Teach Learn Nurs. 2016; 11(4): 204-8.

3. Borycki EM, Frisch N, Moreau J, Kushniruk AW. Integration of electronic health records into nursing education: issues, challenges and limitations. Stud Health Technol Inform. 2015; 208: 88-92

4. Samadbeik M, Fatehi F, Braunstein M, Barry B, Saremian M, Kalhor $F$, et al. Education and training on Electronic Medical Records (EMRs) for health care professionals and students: a Scoping Review. Int J Med Inform. 2020; 142: 104238.

5. Bowers AM, Kavanagh J, Gregorich T, Shumway J, Campbell Y, Stafford S. Student nurses and the electronic medical record: a partnership of academia and healthcare. Comput Inform Nurs. 2011; 29(12): 692-7.

6. Pederson B. EMR in Australia - the state of the nation. Health Informatics Spciety Australia. 2018. Available from: https://www.hisa.org.au/slides/hic18/tue/BrucePedersen.pdf

7. Choi M, Lee HS, Park JH. Usability of Academic Electronic Medical Record Application for Nursing Students' Clinical Practicum. Healthc Inform Res. 2015; 21(3): 191-5.

8. Choi M, Lee H, Park JH. Effects of using mobile device-based academic electronic medical records for clinical practicum by undergraduate nursing students: a quasi-experimental study. Nurse Educ Today. 2018; 61: 112-9

9. Johnson D, Bushey T. Integrating the academic electronic health record into nursing curriculum: preparing student nurses for practice. Comput Inform Nurs. 2011; 29(3): 133-7.

10. Jones S, Donelle L. Assessment of electronic health record usability with undergraduate nursing students. Int J Nurs Educ Scholarsh. 2011; 8: Article 24.

11. Kowitlawakul Y, Wang L, Chan SW. Development of the electronic health records for nursing education (EHRNE) software program. Nurse Educ Today. 2013; 33(12): 1529-35.

12. Elliott K, Marks-Maran D, Bach R. Teaching student nurses how to use electronic patient records through simulation: a case study. Nurse Educ Pract. 2018; 30: 7-12.

13. Herbert VM, Connors H. Integrating an Academic Electronic Health Record: challenges and success strategies. Comput Inform Nurs. 2016; 34(8): 345-54.

14. Gray K, Dattakumar A, Maeder A, Butler-Henderson K, Chenery $\mathrm{H}$. Advancing ehealth education for the clinical health professions: final report. Department of Education Office for Learning and Teaching. 2014

15. Mollart L, Newell R, Geale S, Noble D, Norton C, O'Brien AP. Introduction of patient electronic medical records (EMR) into undergraduate nursing education: an integrated literature review. Nurse Educ Today. 2020; 94(Nov): 104517.

16. Australian Nursing and Midwifery Accreditation Council. Review of Registered Nurse accreditation standards: consultation paper 2. Australian Nursing and Midwifery Council. 2018. Available from: https://www.anmac.org.au/sites/default/files/ documents/rnasconsultationpaper2.pdf

17. University of Newcastle. A NeW Education Framework: an integrated approach. University of Newcastle. 2018
18. Choi M, Park JH, Lee HS. Assessment of the need to integrate Academic Electronic Medical Records into the undergraduate clinical practicum: a focus group interview. Comput Inform Nurs. 2016; 34(6): 259-65.

19. Pobocik T. Using an educational electronic documentation system to help nursing students accurately identify patient data. Int J Nurs Knowl. 2015; 26(1): 26-34.

20. Chung J, Cho I. The need for academic electronic health record systems in nurse education. Nurse Educ Today. 2017; 54: 83-8.

21. Warboys I, Mok WY, Frith KH. Electronic medical records in clinical teaching. Nurse Educ. 2014; 39(6): 298-301.

22. Mountain C, Redd R, O'Leary-Kelly C, Giles K. Electronic medical record in the simulation hospital: does it improve accuracy in charting vital signs, intake, and output? Comput Inform Nurs. 2015; 33(4): 166-71

23. Meyer L, Sternberger $C$, Toscos T. How to implement the electronic health record in undergraduate nursing education. American Nurse Today. 2011; 6(5): 40-4

24. Kowitlawakul Y, Chan S, Pulcini J, Wang W. Factors influencing nursing students' acceptance of electronic health records for nursing education (EHRNE) software program. Nurse Educ Today. 2015; 35(1): 189-94

25. Field A. Discovering statistics using IBM SPSS Statistics. 5th ed. SAGE Edge; 2017

26. Sandelowski M. Focus on research methods-whatever happened to qualitative description? Res Nurs Health. 2000; 23(4): 334-40

27. Merriam SB, Tisdell EJ. Qualitative research: a guide to design and implementation. 4th ed. San Franciso: John Wiley \& Sons Inc; 2016.

28. Kent-Wilkinson A, Dietrich Leurer M, Luimes J, Ferguson L, Murray L. Studying abroad: exploring factors influencing nursing students' decisions to apply for clinical placements in international settings. Nurse Educ Today. 2015; 35(8): 941-7.

29. Sweet L, Broadbent J. Nursing students' perceptions of the qualities of a clinical facilitator that enhance learning. Nurse Educ Pract. 2017; 22: 30-6.

30. Terkes N, Celik F, Bektas H. Determination of nursing students' attitudes towards the use of technology. Jpn J Nurs Sci. 2019; 16(1): 17-24

31. Gonen A, Sharon D, Lev-Ari L, Strauss E, Segev R. The impact of nursing students' cultural diversity on the intention and attitudes toward the use of information technology. J Transcult Nurs. 2016; 27(3): 302-10.

32. Tubaishat A, Aljezawi M, Al-Rawajfah OM, Habiballah L, AkhuZaheya LM. Exploring changes in nursing students' attitudes towards the use of technology: a four-wave longitudinal panel study. Nurse Educ Today. 2016; 38: 101-6.

33. Chamberlain D, Williams A, Stanley D, Mellor P, Cross W, Siegloff L. Dispositional mindfulness and employment status as predictors of resilience in third year nursing students: a quantitative study. Nurs Open. 2016; 3(4): 212-21.

34. Shivers E, Hasson F, Slater P. Pre-registration nursing student's quality of practice learning: clinical learning environment inventory (actual) questionnaire. Nurse Educ Today. 2017; 55: 58-64.

35. Herrmann-Werner A, Holderried M, Loda T, Malek N, Zipfel S, Holderried F. Navigating through electronic health records: survey study on medical students' perspectives in general and with regard to a specific training. JMIR Med Inform. 2019; 7(4): 267-77. 
36. Australian College of Nursing. Nursing informatics position statement. Australian College of Nursing. 2017. Available from: https://www.acn.edu.au/wp-content/uploads/joint-positionstatement-nursing-informatics-hisa-nia.pdf

37. Baillie L, Chadwick S, Mann R, Brooke-Read M. A survey of student nurses' and midwives' experiences of learning to use electronic health record systems in practice. Nurse Educ Pract. 2013; 13(5): 437-41.

38. Australian Commission on Safety and Quality in Healthcare. National safety and quality health service standards. Australian Commission on Saety and Quality in Healthcare. 2017. Available from: https://www.safetyandquality.gov.au/standards/nsqhsstandards

39. Nursing and Midwifery Board of Australia. Code of conduct for nurses. Nursing and Midwifery Board of Australia. 2018.

40. Nursing and Midwifery Board of Australia. Decision-making framework for nursing and midwifery. Nursing and Midwifery Board of Australia. 2020

41. Baxter PM, Andrew LA. Successful integration of an Academic Electronic Health Record into the curriculum of an associate degree nursing program. Nurs Educ Perspect. 2018; 39(4): 250-2.

42. Gardner CL, Jones SJ. Utilization of academic electronic medical records in undergraduate nursing education. Online J Nurs Inform 2012; 16(2): 31-7.

43. DeBlieck C, Mullins I. Electronic Health Record: Faculty Education to Enhance Student Learning (FEESL). J Technol Hum Serv. 2016; 12(1): 1-13.0 